\title{
Partition Dimension of Complete Multipartite Graph
}

\author{
Dimensi Partisi Graf Multipartit Lengkap \\ Safriadi $^{1)}$, Hasmawati ${ }^{2)}$, Loeky Haryanto ${ }^{3)}$
}

\begin{abstract}
Determining a resolving partition of a graph is an interesting study in graph theory due to many applications like censor design, compound classification in chemistry, robotic navigation and internet network. Let $v \in V(G)$ and $S \subseteq V(G)$, the distance between $v$ an $S$ is $d(v, S)=$ $\min \{d(v, x) \mid x \in S\}$. For an ordered partition $\Pi=\left\{S_{1}, S_{1}, \ldots, S_{m}\right\}$ of $V(G)$, the representation of $v$ with respect to $\Pi$ is $r(v \mid \Pi)=\left(d\left(v, S_{1}\right), d\left(v, S_{2}\right), \ldots, d\left(v, S_{m}\right)\right)$. The partition $\Pi$ is called a resolving partition of $G$ if all representation of vertices are distinct. The partition dimension of graph $G$ is the smallest integer $m$ such that $G$ has a resolving partition with $m$ element.

In this thesis, we determine the partition dimension of complete multipartite graph $K_{n_{1}, n_{2}, \ldots, n_{k}, n_{k+1}, \ldots, n_{k+r}}, n_{i} \in N$ which is limited by $=n_{1} \geq n_{2} \geq \cdots \geq n_{k}>n_{k+1} \geq n_{k+2} \geq \cdots \geq$ $n_{k+r-1}=n_{k+r}$, with $k \in\{1,2\}$ and $r \in\{2,3\}$. We found that, $p d\left(K_{n, 2,2}\right)=n+1, n \geq 3$ and $p d\left(K_{n, 2,2,2}\right)=n+3, n \geq 3$.
\end{abstract}

Keywords: multipartite graph, complete multipartite, partition set, resolving partition, partition dimension.

\begin{abstract}
Abstrak
Penentuan partisi pembeda dari suatu graf adalah kajian menarik dalam teori graf karena mempunyai banyak aplikasi seperti perancangan sensor, klasifikasi senyawa kimia, navigasi robot dan jaringan. Misalkan $v \in V(G)$ dan $S \subseteq V(G)$, jarak antara $v$ dan $S$ adalah $d(v, S)=$ $\min \{d(v, x) \mid x \in S\}$. Untuk sebuah partisi $\Pi=\left\{S_{1}, S_{1}, \ldots, S_{m}\right\}$ dari $V(G)$, representasi $v$ terhadap $\Pi$ adalah $r(v \mid \Pi)=\left(d\left(v, S_{1}\right), d\left(v, S_{2}\right), \ldots, d\left(v, S_{m}\right)\right)$. Partisi $\Pi$ disebut partisi pembeda dari $G$ jika semua representasi dari setiap titik $v \in V(G)$ berbeda. Dimensi partisi $p d(G)$ adalah

${ }^{1,2,3)}$ Departemen Matematika, Universitas Hasanuddin

1) safriadi.sape@gmail.com, ${ }^{2)}$ hasmaba97@gmai.com, ${ }^{3)}$ l.haryanto@unhas.ac.id
\end{abstract}




\section{Safriadi, Hasmawati, Loeky Haryanto}

bilangan bulat terkecil $m$ sedemikian sehingga $G$ mempunyai sebuah partisi pembeda dengan $m$ anggota.

Dalam tesis ini, kami menentukan dimensi partisi graf multipartit lengkap $K_{n_{1}, n_{2}, \ldots, n_{k}, n_{k+1}, \ldots, n_{k+r}}$, $n_{i} \in N$ dibatasi dengan $n_{1} \geq n_{2} \geq \cdots \geq n_{k}>n_{k+1} \geq n_{k+2} \geq \cdots \geq n_{k+r-1}=n_{k+r}$, dengan $k \in\{1,2\}$ dan $r \in\{2,3\}$. Kami mendapatakan hasil, $p d\left(K_{n, 2,2}\right)=n+1, n \geq 3$ dan $p d\left(K_{n, 2,2,2}\right)=$ $n+3, n \geq 3$.

Katakunci: graf multipartit, multipartit lengkap, himpunan partisi, partisi pembeda, dimensi partisi.

\section{Pendahuluan}

Graf adalah pasangan himpunan yang anggotanya disebut titik dan himpunan yang anggota-anggotanya adalah pasangan titik yang disebut sisi. Banyak penelitian telah dilakukan pada graf, diantaranya pewarnaan sisi, teori Ramsey pada graf, pelabelan titik partisi dimensi dan lain-lain. Dimensi partisi merupakan permasalahan yang menarik untuk dibahas dan banyak mendapat perhatian dari kalangan peneliti. Beberapa hasil penelitian tentang dimensi partisi pada graph sudah banyak dipublikasikan. Untuk mengetahui dimensi partisi, terlebih dahulu diketahui partisi pembeda. Chartrand dkk. (1998) mengenalkan konsep partisi pembeda yang merupakan bentuk serupa dari himpunan pembeda suatu graf. Chartrand dkk. (1998) melakukan pengelompokan titik di graf $G$ ke dalam sejumlah kelas partisi dan menghitung jarak setiap titik di $G$ terhadap semua kelas partisi untuk merepresentasikan setiap titik pada graf $G$. Himpunan pembeda $W$ memastikan representasi berbeda untuk semua titik di graf $\mathrm{G}$, yaitu dengan menunjukkan jarak titik $v \in V(G)$ ke semua titik di $W \subset V(G)$ dan dimensi metrik memastikan kardinalitas $W$ adalah minimal. Sedangkan partisi pembeda $\Pi$ memastikan representasi berbeda untuk semua titik di graf $G$, yaitu dengan menunjukkan jarak titik $v \in V(G)$ ke semua kelas partisi dalam $\Pi$ dan dimensi partisi $p d(G)$ memastikan kardinalitas $\Pi$ adalah minimal. Chartrand, Salehi dan Zhang (2000) mengawali penelitian dimensi partisi untuk kelas graf multipartit dengan menentukan dimensi partisi graf bipartit. Graf bipartit digunakan dalam beberapa bidang aplikasi, seperti menentukan jenis pekerjaan yang tepat bagi para pelamar sesuai dengan kualifikasi yang dimilikinya. Dalam teori Graf, Chartrand, Salehi dan Zhang mengkaji graf multipartit dan menghasilkan dimensi partisi graf lengkap $r$-partit $K_{n_{1}, n_{2}, \ldots, n_{r}}$ adalah $n+r-1$ jika $n_{i}=n$ untuk $1 \leq i \leq r$, dan $n+r-2$ jika $n=n_{1} \geq n_{2} \geq \cdots>n_{r}$. Dari hasil yang didapatkan ini masih banyak graf lengkap $r$-partit yang belum termuat. Oleh karena itu, dalam penelitian ini akan dikaji Dimensi partisi graf multipartit lengkap. 


\section{Safriadi, Hasmawati, Loeky Haryanto}

\section{Tinjauan Pustaka}

Dimensi partisi dari sebuah graf $G$ dikenalkan oleh Chartrand dkk. Pada tahun 1998. Mereka mengelompokkan semua titik di $G$ ke dalam sejumlah kelas partisi dan menentukan jarak setiap titik terhadap setiap kelas partisi tersebut. Misalkan $u$ dan $v$ adalah titik-titik di graf $G$. Jarak antara titik $u$ dan $v$ dinotasikan dengan $d(u, v)$, misalkan $G=(V, E)$ adalah graf terhubung dan misalkan $S \subseteq V$. Misalkan terdapat suatu titik $v \in V$. Maka jarak titik $v$ terhadap $S$ didefinisikan sebagai $d(v, S)=\min \{d(v, x) \mid x \in S\}$. Misalkan $G$ adalah suatu graf terhubung dengan himpunan titik $V(G)$ dipartisi menjadi beberapa kelas partisi, sebut $S_{1}, S_{2}, \ldots, S_{m}$. Notasikan $\Pi$ sebagai himpunan terurut dari beberapa partisi- $k$, yakni $\Pi=\left\{S_{1}, S_{2}, \ldots, S_{m}\right\}$ disebut himpunan partisi. Misalkan terdapat suatu titik $v$ di $G$, maka representasi $v$ terhadap $\prod$ didefinisikan sebagai jarak dari $v$ ke tiap-tiap partisi di $\prod, r\left((v \mid \Pi)=\left(d\left(v, S_{1}\right), d\left(v, S_{2}\right), \ldots, d\left(v, S_{m}\right)\right)\right.$. Untuk selanjutnya $r((v \mid \Pi)$ ini disebut vektor penyajian. Jika setiap dua titik berbeda $u, v \in V(G)$ berlaku $r((u \mid \Pi) \neq r((v \mid \Pi)$ maka $\prod$ disebut partisi pembeda dari $V(G)$. Partisi pembeda $\prod$ dengan kardinalitas minimum disebut partisi pembeda minimum dari $G$. Dimensi partisi $p d(G)$ dari graf $G$ adalah kardinalitas dari partisi pembeda minimum dari $G$. Misalkan $\Pi=\left\{S_{1}, S_{2}, \ldots, S_{k}\right\}$ adalah himpunan partisi dari $V(G)$. Jika $u \in S_{i}$ dan $v \in S_{j}$, dan $i \neq j$, maka jelas bahwa $r\left((u \mid \Pi) \neq r\left((v \mid \Pi)\right.\right.$ (karena $d\left(u, S_{i}\right)=0$ tetapi $\left.d\left(v, S_{i}\right) \neq 0\right)$. Dengan demikian, ketika diberikan sebuah partisi $\prod$ dari $V(G)$ dan hendak menentukan apakah $\prod$ adalah partisi pembeda untuk $V(G)$ atau bukan, pemeriksaan cukup dilakukan pada semua titik yang termasuk dalam suatu kelas partisi yang sama. Jika semua titik dalam setiap kelas partisi yang sama mempunyai representasi berbeda terhadap $\prod$, maka $\prod$ merupakan partisi pembeda. Jika $d\left(u, S_{i}\right) \neq d\left(v, S_{i}\right)$, maka kelas partisi $S_{i}$ dikatakan memisahkan titik $u$ dan $v$ di $G$. Sebuah kelas partisi yang mempunyai satu anggota disebut kelas partisi singleton. Dengan sendirinya, titik dalam kelas partisi singleton mempunyai representasi yang unik.

\section{Hasil Dan Pembahasan}

Diberikan graf multipartit $K_{3,2,2}$ dengan partisi $V_{1}=\left\{x_{1}, x_{2}, x_{3}\right\}, V_{2}=\left\{y_{1}, y_{2}\right\}$, dan $V_{3}=\left\{z_{1}, z_{2}\right\}$. Misalkan pula $\Pi=\left\{S_{1}, S_{2}, S_{3}\right\}$ dengan $S_{1}=\left\{x_{1}, z_{1}\right\}, S_{2}=\left\{x_{2}, y_{2}\right\}$, dan $S_{3}=\left\{x_{3}, y_{1}, z_{2}\right\}$ representasi titik yang ada pada kelas partisi yang sama.

$$
\mathrm{S}_{1} \quad \mathrm{~S}_{2} \quad \mathrm{~S}_{3}
$$




\section{Safriadi, Hasmawati, Loeky Haryanto}

$\begin{array}{llll}\mathrm{r}\left(x_{1} \mid \pi\right)=0 & 1 & 1 \\ \mathrm{r}\left(y_{1} \mid \pi\right)=1 & 1 & 0 \\ \mathrm{r}\left(z_{2} \mid \pi\right)=1 & 1 & 0 .\end{array}$

Jadi $\Pi=\left\{S_{1}, S_{2}, S_{3}\right\}$ bukan partisi pembeda, $p d\left(K_{3,2,2}\right) \geq 4$

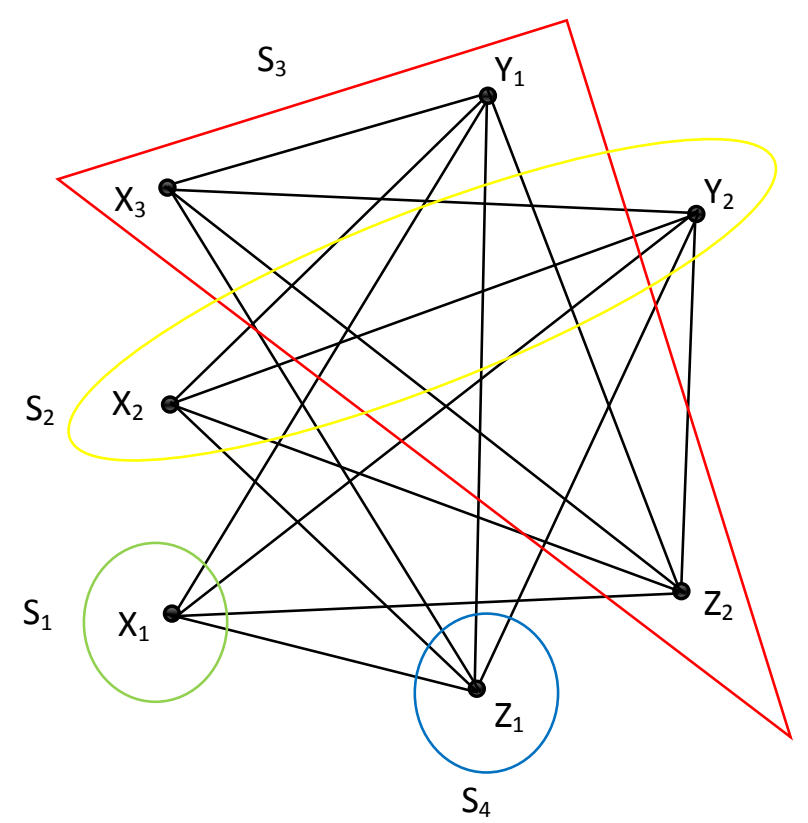

\begin{tabular}{|c|c|c|c|}
\hline $\mathrm{S}_{1}$ & & $\mathrm{~S}_{2}$ & $\mathrm{~S}_{3}$ \\
\hline $\mathrm{r}\left(\mathrm{x}_{1} \mid \pi\right)=$ & 0 & 1 & 1 \\
\hline $\mathrm{r}\left(\mathrm{x}_{2} \mid \pi\right)=$ & 2 & 0 & 1 \\
\hline $\mathrm{r}\left(\mathrm{x}_{3} \mid \pi\right)=$ & 2 & 1 & 0 \\
\hline $\mathrm{r}\left(\mathrm{y}_{1} \mid \pi\right)=$ & 1 & 1 & 0 \\
\hline $\mathrm{r}\left(\mathrm{y}_{2} \mid \pi\right)=$ & 1 & 0 & 1 \\
\hline $\mathrm{r}\left(\mathrm{z}_{1} \mid \pi\right)=$ & 1 & 1 & 1 \\
\hline $\mathrm{r}\left(\mathrm{z}_{2} \mid \pi\right)=$ & 1 & 1 & 0 \\
\hline
\end{tabular}

Terlihat bahwa refresentasi setiap titik terhadap $\pi$ semua berbeda. Jadi $\pi$ merupakan partisi pembeda. Karena $|\pi|=4$, menurut definisi diperoleh $p d\left(K_{3,2,2}\right) \leq 4$.

Dari hasil (1) dan (2), diperoleh $p d\left(K_{3,2,2}\right)=4$. 


\section{Safriadi, Hasmawati, Loeky Haryanto}

Dengan cara yang serupa dapat diperoleh $p d\left(K_{4,2,2}\right)=5$ dan $p d\left(K_{5,2,2}\right)=6$. Hasil ini secara umum dirangkum dalam teorema berikut.

Teorema 1. Jika $n \geq 3$, maka $p d\left(K_{n, 2,2}\right)=n+1$

Bukti.

Misalkan $V_{i, j}$ adalah partisi ke- $i$ dengan berkardinalitas $j$. Dengan menginduksi di $n \geq 3$

1. untuk $n=3, p d\left(K_{3,2,2}\right)=4$ benar

2. asumsikan Teorema benar untuk $n=l$, yaitu $p d\left(K_{l, 2,2}\right)=l+1$ dengan $V\left(K_{l, 2,2}\right)=$ $V_{1, l} \cup V_{2,2} \cup V_{3,2}$ dan partisi pembeda $\Pi=\left\{S_{1}, \ldots S_{l+1}\right\}$, dengan $v_{i} \in S_{i}, i=1,2, \ldots l$ dan zi $\in S_{l+1}$.

3. akan ditunjukkan bahwa Teorema juga benar untuk $n=l+1$, yaitu akan dibuktikan bahwa $p d\left(K_{l+1,2,2}\right)=l+2$. Mengingat $V_{1, l+1} \cup V_{2,2} \cup V_{3,2}=V_{1, l} \cup\left\{v_{l+1}\right\} \cup V_{2,2} \cup$ $V_{3,2}=V_{1, l} \cup V_{2,2} \cup V_{3,2} \cup\left\{v_{l+1}\right\}$. Menurut asumsi $v_{l} \in S_{i}$, untuk $i=1,2 \ldots l$, dan $z \in S_{l+1}$ untuk suatu $i$ bentuk himpunan partisi $\Pi^{\prime}=\left\{S_{1}, \ldots S_{l}, S_{l+1}, S_{l+2}\right\}$ dengan $v_{l+1} \in S_{l+2}$ dengan demikian $\prod^{\prime}=\prod \cup\left\{S_{l+2}\right\}$.

Langkah selanjutnya adalah menunjukkan bahwa himpunan partisi $\Pi^{\prime}$ dari $K_{l+1,2,2}$ merupakan partisi pembeda. Hubungan antara asumsi (2) dengan (3): $\Pi^{\prime}=$ $\Pi \cup\left\{S_{l+2}\right\}$ yaitu $\Pi^{\prime}$ partisi pembeda.

Karena $\Pi$ adalah partisi pembeda $K_{l, 2,2}$ yaitu untuk setiap titik pada partisi graf $V_{1, l} \cup$ $V_{2,2} \cup V_{3,2}$, maka $\forall u, v \in V_{1, l} \cup V_{2,2} \cup V_{3,2}$, jarak antara titik $u$ dan $v$ terhadap $\Pi^{\prime}$ juga berbeda atau $r(u \mid \Pi) \neq(v \mid \Pi)$. Dengan demikian, untuk setiap $u, v \in V_{1, l} \cup V_{2,2} \cup$ $V_{3,2}$ berlaku jarak antara titik $u$ dan $v$ terhadap $\Pi$ berbeda atau $r\left(u \mid \Pi^{\prime}\right) \neq r\left(v \mid \Pi^{\prime}\right)$. Karena $v_{l+1} \in S_{l+2}$, maka $d\left(v_{l+1}, S_{l+2}\right)=0$ sedangkan $d\left(v, S_{l+2}\right) \neq 0, \forall v \in V_{1, l} \cup$ $V_{2,2} \cup V_{3,2}$. Akibatnya, untuk setiap $v, w \in V_{1, l+1} \cup V_{2,2} \cup V_{3,2}, r\left(v \mid \Pi^{\prime}\right) \neq r\left(w \mid \Pi^{\prime}\right)$. Jadi $\Pi^{\prime}$ merupakan partisi pembeda untuk graf $K_{l+1,2,2}$. Banyaknya anggota dari $\Pi^{\prime}$ 
adalah $\left|\Pi^{\prime}\right|=|\Pi|+1=l+2$. Jadi $p d\left(K_{l+1,2,2}\right)=l+2$. Dengan demikian, dapat dikatakan bahwa $p d\left(K_{n, 2,2}\right)=n+1, \forall n \in N$

Selanjutnya akan dibentuk partisi pembeda dari graf $K_{n, 2,2,2}$

a) Diberikan graf multipartit $K_{3,2,2,2}$, dalam hal ini $n_{1}=3, n_{2}=n_{3}=n_{4}=2$ dengan partisi $V_{1}=\left\{w_{1}, w_{2}, w_{3}\right\}, \quad V_{2}=\left\{x_{1}, x_{2}\right\}, \quad V_{3}=\left\{y_{1}, y_{2}\right\} \quad$ dan $V_{4}=\left\{z_{1}, z_{2}\right\}$. Misalkan pula $S_{1}=\left\{w_{1}, y_{2}\right\}, S_{2}=\left\{w_{2}, z_{1}\right\}, S_{3}=\left\{w_{3}\right\}, S_{4}=\left\{x_{1}, z_{2}\right\}, S_{5}=\left\{x_{2}, y_{1}\right\}$. Jadi $\Pi=\left\{\mathrm{S}_{1}, \mathrm{~S}_{2}, \ldots, \mathrm{S}_{5}\right\}$. Refresentasi setiap titik di $K_{3,2,2,2}$, terhadap $\Pi$ tidak semua berbeda. Jadi $\Pi=\left\{\mathrm{S}_{1}, \mathrm{~S}_{2}, \ldots, \mathrm{S}_{5}\right\}$ bukan partisi pembeda. Dengan demikian, $p d\left(K_{3,2,2,2}\right) \geq 6$.

Selanjuta, pilih kelas partisi seperti berikut. $S_{1}=\left\{w_{1}, y_{2}\right\}, S_{2}=\left\{w_{2}, z_{1}\right\}, S_{3}=\left\{w_{3}\right\}$, $S_{4}=\left\{x_{1}, z_{2}\right\}, S_{5}=\left\{x_{2}\right\}, S_{6}=\left\{y_{1}\right\}$. Jadi $\Pi=\left\{S_{1}, S_{2}, \ldots, S_{5}, S_{6}\right\}$. Refresentasi setiap titik di $K_{3,2,2,2}$, Kelas partsi $\mathrm{S}_{1}, \mathrm{~S}_{2}, \ldots, \mathrm{S}_{5}, S_{6}$ dapat dilihat dalam gambar. Selanjutnya, dapat diperiksa refresentasi setiap titik di $K_{3,2,2,2}$, terhadap $\Pi$ seperti yang diuraikan berikut. Ternyata semua berbeda. Jadi $\Pi=\left\{\mathrm{S}_{1}, \mathrm{~S}_{2}, \ldots, \mathrm{S}_{5}, \mathrm{~S}_{6}\right\}$ merupakan partisi pembeda. Dengan demikian, $p d\left(K_{3,2,2,2}\right) \leq 6$.

Dari (3) dan (4) diperoleh $p d\left(K_{3,2,2,2}\right)=6$.

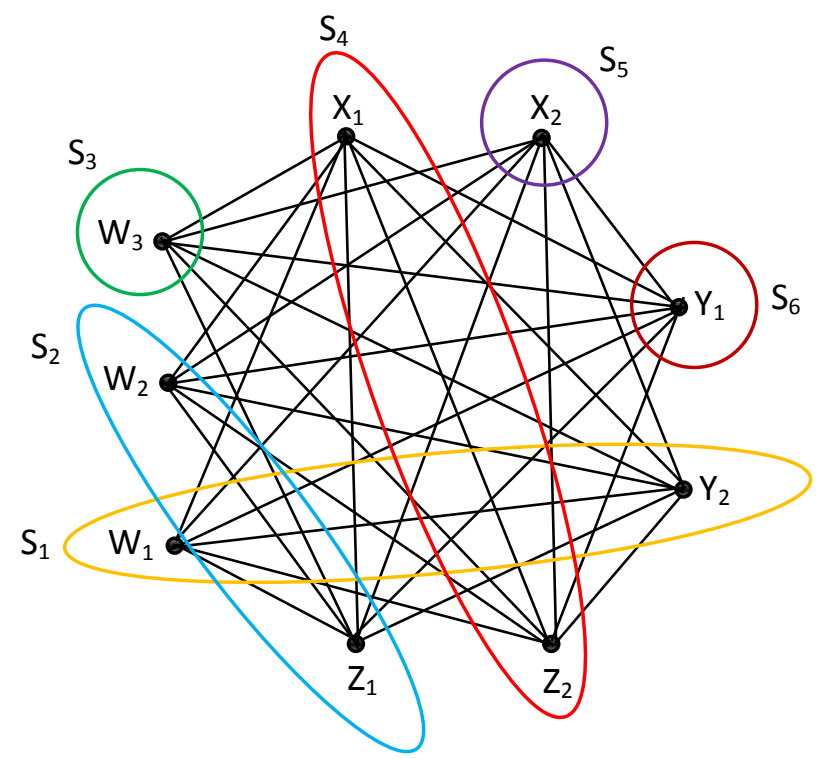

$\mathrm{S}_{1}$

$\mathrm{S}_{2}$

$\mathrm{S}_{3}$

$\mathrm{S}_{4}$

$\mathrm{S}_{5}$

$\mathrm{S}_{6}$ 


\begin{tabular}{|c|c|c|c|c|c|}
\hline $\mathrm{r}\left(\mathrm{W}_{1} \mid \pi\right)=$ & 0 & 1 & 2 & 1 & 1 \\
\hline $\mathrm{r}\left(\mathrm{W}_{2} \mid \pi\right)=$ & 1 & 0 & 2 & 1 & 1 \\
\hline $\mathrm{r}\left(\mathrm{W}_{3} \mid \pi\right)=$ & 1 & 1 & 0 & 1 & 1 \\
\hline $\mathrm{r}\left(\mathrm{X}_{1} \mid \pi\right)=$ & 1 & 1 & 1 & 0 & 2 \\
\hline $\mathrm{r}\left(\mathrm{X}_{2} \mid \pi\right)=$ & 1 & 1 & 1 & 1 & 0 \\
\hline $\mathrm{r}\left(\mathrm{Y}_{1} \mid \pi\right)=$ & 1 & 1 & 1 & 1 & 1 \\
\hline $\mathrm{r}\left(\mathrm{Y}_{2} \mid \pi\right)=$ & 0 & 1 & 1 & 1 & 1 \\
\hline $\mathrm{r}\left(\mathrm{Z}_{1} \mid \pi\right)=$ & 1 & 0 & 1 & 1 & 1 \\
\hline $\mathrm{r}\left(\mathrm{Z}_{2} \mid \pi\right)=$ & 1 & 1 & 1 & 0 & 1 \\
\hline
\end{tabular}

Misalkan $n_{1}=4, n_{2}=n_{3}=n_{4}=2$ atau $K_{4,2,2,2}$ dengan partisi $V_{1}=\left\{w_{1}, w_{2}, w_{3}\right\}$, $V_{2}=\left\{x_{1}, x_{2}\right\}, V_{3}=\left\{y_{1}, y_{2}\right\}$ dan $V_{4}=\left\{z_{1}, z_{2}\right\}$. Misalkan pula $S_{1}=\left\{w_{1}, y_{2}\right\}, S_{2}=$ $\left\{w_{2}, z_{1}\right\}, \quad S_{3}=\left\{w_{3}\right\}, \quad S_{4}=\left\{w_{4}\right\} \quad S_{5}=\left\{x_{1}, z_{2}\right\}, S_{6}=\left\{x_{2}\right\}, \quad S_{7}=\left\{y_{1}\right\} \quad$. Jadi $\Pi=$ $\left\{\mathrm{S}_{1}, \mathrm{~S}_{2}, \ldots, \mathrm{S}_{5}, \mathrm{~S}_{6}, \mathrm{~S}_{7}\right\}$.

Representasi setiap titik $K_{4,2,2,2}$ terhadap $\Pi$ diperoleh

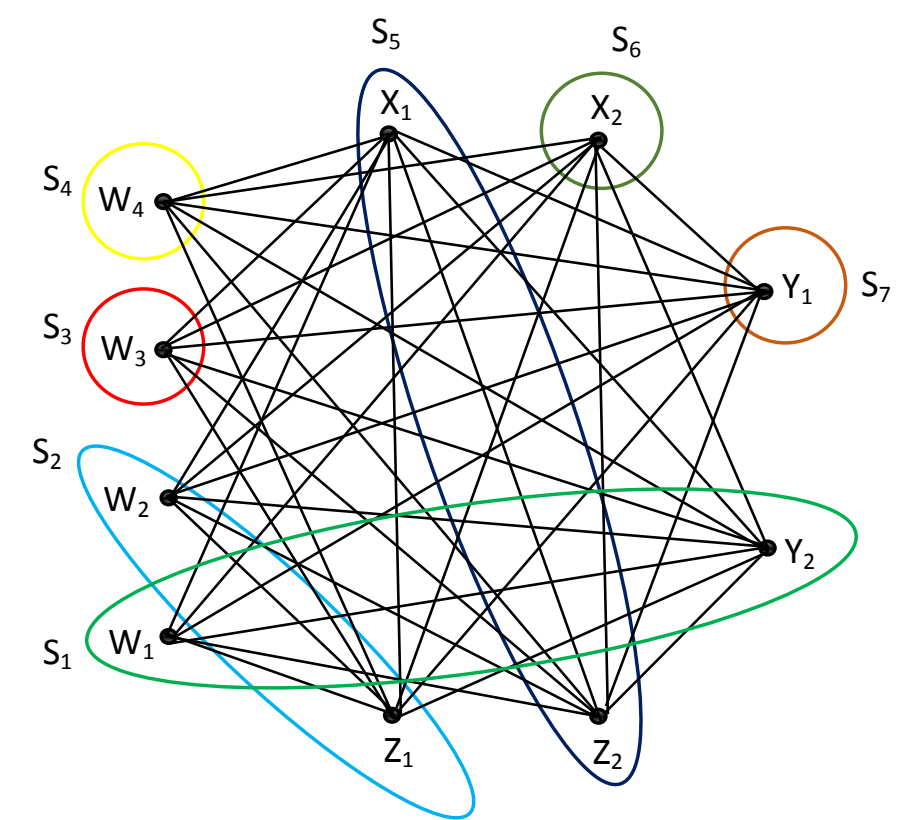

$\begin{array}{lllllll}\mathrm{S}_{1} & \mathrm{~S}_{2} & \mathrm{~S}_{3} & \mathrm{~S}_{4} & \mathrm{~S}_{5} & \mathrm{~S}_{6} & \mathrm{~S}_{7}\end{array}$ 


\section{Safriadi, Hasmawati, Loeky Haryanto}

\begin{tabular}{|c|c|c|c|c|c|c|}
\hline $\mathrm{r}\left(\mathrm{W}_{1} \mid \pi\right)=$ & 0 & 1 & 2 & 2 & 1 & 1 \\
\hline $\mathrm{r}\left(\mathrm{W}_{2} \mid \pi\right)=$ & 1 & 0 & 2 & 2 & 1 & 1 \\
\hline $\mathrm{r}\left(\mathrm{W}_{3} \mid \pi\right)=$ & 1 & 1 & 0 & 2 & 1 & 1 \\
\hline $\mathrm{r}\left(\mathrm{W}_{4} \mid \pi\right)=$ & 1 & 1 & 2 & 0 & 1 & 1 \\
\hline$r\left(X_{1} \mid \pi\right)=$ & 1 & 1 & 1 & 1 & 0 & 2 \\
\hline$r\left(X_{2} \mid \pi\right)=$ & 1 & 1 & 1 & 1 & 2 & 0 \\
\hline $\mathrm{r}\left(\mathrm{Y}_{1} \mid \pi\right)=$ & 1 & 1 & 1 & 1 & 1 & 1 \\
\hline $\mathrm{r}\left(\mathrm{Y}_{2} \mid \pi\right)=$ & 0 & 1 & 1 & 1 & 1 & 1 \\
\hline $\mathrm{r}\left(\mathrm{Z}_{1} \mid \pi\right)=$ & 1 & 0 & 1 & 1 & 1 & 1 \\
\hline $\mathrm{r}\left(\mathrm{Z}_{2} \mid \pi\right)=$ & 1 & 1 & 1 & 1 & 0 & 1 \\
\hline
\end{tabular}

Maka himpunan partisi untuk $K_{4,2,2,2}$ adalah $\Pi=\left\{S_{1}, S_{2}, S_{3}, S_{4}, S_{5}, S_{6}, S_{7}\right\}$ merupakan partisi pembeda. Jadi $p d\left(K_{4,2,2,2}\right)=7$.

Dengan cara yang serupa dapat diperoleh $p d\left(K_{5,2,2,2}\right)=8$. Hasil ini secara umum dirangkum dalam teorema berikut.

Teorema 2. Jika $n \geq 3$, maka $p d\left(K_{n, 2,2,2}\right)=n+3$

Bukti:

Misalkan $V_{i, j}$ adalah partisi ke- $i$ dengan berkardinalitas $j$. Dengan menginduksi di $n \geq 3$

1. untuk $n=3, \operatorname{pd}\left(K_{3,2,2,2}\right)=6$ benar

2. asumsikan Teorema benar untuk $n=l$, yaitu $\operatorname{pd}\left(K_{l, 2,2,2}\right)=l+3$ dengan $V\left(K_{l, 2,2,2}\right)=V_{1, l} \cup V_{2,2} \cup V_{3,2} \cup V_{4,2}$ dan partisi pembeda $\Pi=\left\{S_{1}, \ldots S_{l+1}\right\}$, dengan $v_{i} \in S_{i}, i=1,2, \ldots l$ dan $z_{i} \in S_{i+1}$

3. akan ditunjukkan bahwa Teorema juga benar untuk $n=l+1$, yaitu akan dibuktikan bahwa $p d\left(K_{l+1,2,2,2}\right)=l+4$. Mengingat $V_{1, l+1} \cup V_{2,2} \cup V_{3,2} \cup V_{4,2}=$ $V_{1, l} \cup\left\{v_{l+1}\right\} \cup V_{2,2} \cup V_{3,2} \cup V_{4,2}=V_{1, l} \cup V_{2,2} \cup V_{3,2} \cup V_{4,2} \cup\left\{v_{l+1}\right\} . \quad$ Menurut 


\section{Safriadi, Hasmawati, Loeky Haryanto}

asumsi $v_{l} \in S_{i}$, untuk $i=1,2, \ldots l$, dan $z_{i} \in S_{i+1}$ untuk suatu $i$ bentuk himpunan partisi $\Pi^{\prime}=\left\{S_{1}, \ldots S_{l}, S_{l+1}, S_{l+2}, S_{l+3}, S_{l+4}\right\}$ dengan $v_{l+} \in S_{l+4}$ dengan demikian $\prod^{\prime}=\prod \cup\left\{S_{l+4}\right\}$

Langkah selanjutnya adalah menunjukkan bahwa himpunan partisi $\Pi^{\prime}$ dari $K_{l+1,2,2,2}$ merupakan partisi pembeda. Hubungan antara asumsi (2) dengan (3): $\prod^{\prime}=\prod \cup\left\{S_{l+4}\right\}$ yaitu $\Pi^{\prime}$ partisi pembeda.

Karena $\Pi$ adalah partisi pembeda $K_{l, 2,2,2}$ yaitu untuk setiap titik pada partisi graf $V_{1, l} \cup V_{2,2} \cup V_{3,2} \cup V_{4,2}$, maka $\forall u, v \in V_{1, l} \cup V_{2,2} \cup V_{3,2} \cup V_{4,2}$, jarak antara titik $u$ dan $v$ terhadap $\Pi$ berbeda atau $r(u \mid \Pi) \neq(v \mid \Pi)$. Dengan demikian, untuk setiap $u, v \in V_{1, l} \cup V_{2,1} \cup V_{3,1} \cup V_{4,1}$ berlaku jarak antara titik $u$ dan $v$ terhadap $\Pi^{\prime}$ juga berbeda atau $r\left(u \mid \Pi^{\prime}\right) \neq\left(v \mid \Pi^{\prime}\right)$. Karena $v_{l+1} \in S_{l+4}$, maka $d\left(v_{l+1}, S_{l+4}\right)=0$ sedangkan $d\left(v, S_{l+4}\right) \neq 0, \forall v \in V_{1, l} \cup V_{2,2} \cup V_{3,2} \cup V_{4,2}$. Akibatnya, untuk setiap $v, w \in V_{1, l+1} \cup V_{2,2} \cup V_{3,2} \cup V_{4,2}, r\left(u \mid \Pi^{\prime}\right) \neq r\left(w \mid \Pi^{\prime}\right)$. Jadi $\Pi^{\prime}$ merupakan partisi pembeda untuk graf $K_{l+1,2,2,2}$. Banyaknya anggota dari $\Pi^{\prime}$ adalah $\left|\Pi^{\prime}\right|=|\Pi|+$ $1=l+4$. Jadi $p d\left(K_{l+1,2,2,2}\right)=l+4$. Dengan demikian, dapat dikatakan bahwa $p d\left(K_{n, 2,2,2,}\right)=n+3, \forall n \in N$

\section{Kesimpulan}

Penelitian dalam tesis ini melengkapi hasil penelitian sebelumnya, seperti dimensi partisi pada graf multipartit lengkap. Penelitian ini telah mendapatkan dimensi partisi graf multipartit lengkap untuk $K_{n_{1}, n_{2}, \ldots, n_{k}, n_{k+1}, \ldots, n_{k+r}}$ untuk $n_{i} \in N$ dan hanya dibatasi oleh $n_{1} \geq n_{2} \geq \cdots \geq n_{k}>n_{k+1} \geq n_{k+2} \geq \cdots \geq n_{k+r-1}=n_{k+r} \quad$ dimana $\quad k \in\{1,2\} \quad$ dan $r \in\{2,3\}$. Selanjutnya diperoleh jika $k=1$ dan $r=2$, maka $p d\left(K_{n, 2,2}\right)=n+1$ untuk $n \geq 3$. Dan jika $k=1$ dan $r=3$, maka $p d\left(K_{n, 2,2,2}\right)=n+3$ untuk $n \geq 3$. 


\section{Safriadi, Hasmawati, Loeky Haryanto}

\section{Daftar Pustaka}

[1] Chartrand, G., Salehi, E. dan Zhang, P. 2000. The partition dimension of a graph. Aequationes Mathematicae.

[2] Chartrand, G.,. dan Zhang, P. Salehi, E. 1998. On the partition dimension of a graph. Congressus Numerantium.

[3] Fehr, M., Gosselin, S. Dan Oellermann, O. 2006. The partition dimension of Cayley digraphs. Aequationes Mathematicae.

[4] Garey, M. dan Johnson, D. 1979. Computers and Intractability: A Guide to the Theory of NP-completeness, W.H. Freeman: California.

[5] Gross, J.L. dan Yellen, J. 2004. Hand Book of Graph Theory. CRC Press LLC: Florida

[6] Hasmawati. 2007. Bilangan Ramsey Untuk Graf Gabungan Bintang. Disertasi tidak diterbitkan. Bandung : Program Pascasarjana ITB.

[7] Javaid, I. Dan Shokat, S. 2008. On the partition dimension of some wheel related graphs. Journal of prime Research in Mathematics.

[8] Lipschutz dan Lipson. 2002. Matematika diskrit. Salemaba teknika: jakarta.

[9] Melter, R. Dan Tomescu, I. 1984. Metric bases in digital geometri. Computer vision Graphics and image Processing.

[10] Tomescu, I. 2008. Discrepancies between metric dimension and partition dimension of a connected graph, Discrete Mathematics.

[11] Tomescu, I., Javaid, I. dan Slamin. 2007. On the partition dimension and connected partition dimension of wheels. Ars Combinatoria. 